\title{
OUTRAS LEITURAS E VISUALIDADES NA FORMAÇÃO DOCENTE EM ARTE
}

\section{Resumo}

O presente artigo aborda a formação docente sob uma perspectiva da inclusão de histórias pessoais. Por meio de uma reflexão crítica acerca das múltiplas possibilidades de apreensão das visualidades no mundo contemporâneo, busca-se apresentar uma avaliação sobre os procedimentos comuns presentes nos processos de formação docente em arte. Muitas vezes, por tomar como base unicamente a transmissão de conteúdos, as referências pessoais do leitor e sua repercussão no ato da compreensão estão geralmente ausentes destes processos, o que acarreta a ausência daquele que está envolvido no processo de compreensão da imagem, de si e do mundo via educação. Em contraposição a esta perspectiva, são apresentadas propostas que possibilitem uma melhor conexão entre os lugares, as vivências pessoais e o conhecimento legitimado sobre arte e de tantas outras visualidades que permeiam nosso cotidiano.

Palavras-chave:

Objeto, memória, formação docente em arte visual. 


\section{FURTHER READINGS AND VISUALITIES IN ART TEACHING FORMATION}

RONALDO ALEXANDRE DE OLIVEIRA
Abstract
This article discusses teaching education from the perspective of the inclusion of personal stories. Through a critical analysis of the multiple possibilities of apprehension of visualities in contemporary world, we seek to provide an assessment on the common procedures in the processes of teacher training in art. Very often, the basis of such methodology is the teaching of art as content transmission; personal references of the reader and their impact upon the understanding of these processes are generally absent, and this implies the absence of the one who is involved in the process of apprehension of the image, of him/herself as well as of the world through Education. In contrast to this perspective, proposals are made to enable a better connection between context, personal experiences and the legitimized knowledge on art and on so many other visualities which permeate our daily lives.

Keywords: Object, memory, art teaching education. 
(...) Imagens têm vida cultural e exercem poder psicológico e social sobre os indivíduos. Este é o principio que fundamenta e orienta a cultura visual. (...). (MARTINS, 20o8, p.34).

E mbora, intrinsecamente, sempre ligado às questões vinculadas à Cultura Visual no processo de formação docente, nunca me coloquei como um estudioso deste campo. Penso que talvez sejam duas as razões para esse posicionamento (de forma muito intuitiva), pois, nunca parei e disse a mim mesmo que a partir daquele determinado momento ia ou não inserir-me neste campo denominado de Cultura Visual. A primeira, talvez, a falta de coragem em alocar-me junto com minhas práticas formativas no guarda-chuva maior da Cultura Visual. A segunda, não tão seguro assim, porque acreditava que os autores com os quais fazia minhas interlocuções, iam dando conta de circunscrever minhas inquietações, minhas buscas e também daqueles com os quais partilhava e compartilho o momento da formação.

Desta maneira, neste texto que segue, não tenho nenhuma pretensão de traçar ou mesmo me debruçar sobre conceitos tão caros à Cultura Visual (trabalho já feito por muitos pesquisadores brasileiros e estrangeiros), mas sim discorrer sobre os modos como penso e tenho praticado a formação docente em Artes Visuais. Meu desejo é que, ao explicitar minhas reflexões, eu possa situar um possível leitor do lugar de onde vejo e pratico a educação e assim, se possível, estabelecer conexões entre questões caras à Cultura Visual e, consequentemente, sua repercussão no processo educacional.

A citação de Raimundo Martins (2008) que encabeça este texto me assegura e me guia neste desvelamento da prática formativa que quero aqui compartilhar. Pois creio que assim como ele nos fala que as "imagens tem vida cultural e exer- 
cem poder psicológico e social sobre os indivíduos", (p.34), assim também, desejo que, ao narrar processos, possa entrever nuances e aproximações destas práticas com o universo da Cultura Visual. Reconforta-me, a cumplicidade dialógica com Martins, quando ele afirma que é "este o princípio que fundamenta e orienta a cultura visual. (...)" (MARTINS, 2008, p.34).

O que busco trazer aqui é uma reflexão sobre o que chamo de metodologia da presença. Uma metodologia para a formação docente em Artes Visuais, em que o sujeito que se forma vislumbra, em seus processos formativos, a sua própria vida, sua própria história. Memória, espaço e lugar tem constituído o mote desencadeador deste processo de formação que se configura nos e a partir dos objetos pessoais.

Estas são visualidades que vêm à tona num processo, muitas vezes tenso, conflituoso; nem sempre diz respeito a lembranças ou memórias ternas, doces, ou aprazíveis. Este é um processo de vida e morte. Envolve um constante lembrar para esquecer, lembrar para renascer, e ainda, lembrar para se ver no outro. Nesta perspectiva, a formação docente em Artes Visuais nos indica o quanto um universo mais amplo da imagem pode e deve fazer parte da formação. É preciso ir além das imagens produzidas e legitimadas historicamente. Uma metodologia da presença clama por outras visualidades; clama pela presença deste sujeito que vive a vida e com ela constrói seus objetos, seus artefatos culturais e simbólicos. Estes são depositários e relicários da sua própria constituição e também da sua transformação.

\section{Iniciando a conversa ou a narrativa de uma pequena história}

Esta é uma incursão por lugares, por paisagens que compõem nossa própria história. Tais espaços culturais estão sempre vivos em nossos procedimentos, e quando os negamos ou os abafamos na gaveta do esquecimento, estamos retirando da educação um de seus aspectos mais ricos. Os processos formativos (sejam eles em que nível for) precisam recuperar esta perspectiva; precisam incluir os seus sujeitos, e, consequentemente, estas trajetórias. Com base em uma análise da importância da história pessoal e seus lugares é que se dá a perspectiva de formação docente em Artes Visuais que dimensiona a compreensão da imagem, a partir da confluência de espaços culturais, e da localização destas leituras no espaço individual dos leitores. 
Exemplos indicam o quanto estudantes e docentes podem permanecer isolados nas próprias leituras que fazem, e não se reconhecerem no processo educativo.

Como perspectiva para a inclusão dos lugares dos sujeitos da educação (educador e educando), é que trago situações que tenho vivenciado nos processos formativos onde somos instigados a refazer um caminho no sentido de encontrar ou reencontrar uma metodologia da presença, em que a narrativa e os objetos pessoais tem delineado os caminhos.

\section{Histórias de vida e o sentido da formação do- cente}

Todo processo de formação parte de um determinado ponto de vista, de um determinado lugar. Formamos a partir das nossas trajetórias, vivências e experiências. Professamos a docência sempre a partir daquilo que temos enquanto repertório - seja ele construído de maneira formal ou informal. Toda formação revela aquilo que temos agregado ao longo da vida. Saber ler, interpretar e compreender nossas trajetórias, muitas vezes, não é tarefa fácil. Pois, ler é descobrir, ler é revelar, mas é, sobretudo, acrescentar e ressignificar. Diferentes lugares e diferentes tempos definem nossas leituras, sendo que, em cada ato de ler, somos outros leitores. A cada leitura, nos situamos em outros espaços, sejam eles físicos geográficos ou simbólicos. Estas são infinitas possibilidades de nos refazermos o tempo todo. Temos sempre a possibilidade de reinvenção daquilo que nos constitui. Podemos ser outros, ser mais. Esta perspectiva da leitura é a que me/nos conduz a pensar sobre a formação docente calcada em processos pessoais, biográficos. O lugar da formação é um espaço de intersecção de histórias de vida, e, assim, revela nossas marcas e cicatrizes pessoais e profissionais.

Esta perspectiva é contrastada com os processos formativos que castram essas possibilidades de reinvenção. Metodologias e currículos cuidam de evitar múltiplos olhares e negam a todo custo as referências pessoais. Fórmulas, roteiros, receitas e sistemas compõem uma trilha estreita e árida que o educador e educando são obrigados a percorrer. A leitura, neste caso, torna-se um ato mecânico, desprovida de sentido pessoal, desprovida das referências daquele que lê.

A escritura deste texto não é diferente. Ao escrever, construo meu pensamento, na perspectiva daquilo que vivi. Meu texto revela os espaços/lugares profissionais e pessoais por 
onde andei. Revela o que li ou deixei de ler. Expressa, de algum modo, a experiência e presença daqueles com os quais dialoguei e dialogo. Aqui estão presentes minhas próprias vivências enquanto professor de arte.

São espaços/lugares profissionais e pessoais desvelados de maneira sutil. Isto me faz indagar: por onde andei? Gente, casa, escola, cidade, país - tantas histórias se formaram nestas mais de duas décadas de magistério! Tal percurso perpassa os mais diversos níveis de ensino - da escola básica à Universidade. Perpassa também os currículos com os quais trabalhei. Alguns destes currículos pude reinventar. Outros, fui obrigado apenas a cumprir. Este percurso me conduziu por correntes pedagógicas limitadoras, e também por aquelas que alimentaram o sentido do humano, que no caminhar constante que incita e instiga à busca, tive a possibilidade de ler, delinear, desenhar.

Desta forma, me vejo revisitando minha própria história. Leio (em pensamentos e anotações) minha própria experiência expressa nas memórias daquilo que escrevi, e, de certo modo, construí a respeito da leitura e formação. Vejo-me procurando por um caminho que dê forma e inclua aquilo que não poderia ficar ausente. Mesmo este espaço das ideias, da escrita não poderia deixar de incluir história e presença. Uma escrita e leitura que sejam significativas precisam incluir os seus sujeitos.

Este processo se dá resgatando antigos guardados, fragmentos do tempo, memórias, livros, objetos. Este é um professor que revisita seu baú e de lá resgata suas próprias vivências, experiências, projetos. Neste processo, dou-me conta de que me tornei o que sou graças a um constante recolher de elementos. Vejo então as marcas deixadas pela minha experiência, seja como produtor de imagens, educador ou pesquisador. E neste momento dou vazão à afetividade que também carrego. O ser professor não elimina minha conexão afetiva com as marcas de minhas vivências. Como afirma Alberoni, é preciso "restituir espaço à emoção, ao amor, ao entusiasmo, à piedade, à benevolência, ao respeito, ao cuidado" (ALBERONI apud MONTEIRO, 2002, p 48). É necessário que haja biografias e histórias. É fundamental que haja pessoas que saibam existir além de sua manifestação. Que haja um sentido de responsabilidade sobre nossas realizações. "Que nos curvemos para o passado, estejamos empenhados pelo futuro e saibamos reconhecer nas outras pessoas a nossa própria natureza" (ALBERONI Apud MONTEIRO, 2002, p. 48).

Os argumentos de Alberoni (2000) elucidam e encorajam-me a buscar cada vez mais um caminho/metodologia 
que, de fato, atenda às verdadeiras necessidades do processo de formação. Uma metodologia da presença envolve um ato de criação nascido a partir daquele que se propõe a ler e a educar. Como argumenta Monteiro sobre construção das biografias,

\begin{abstract}
A história de vida na forma de narrar autobiografia e biografia permite não só ao próprio sujeito pesquisado refletir sua existência pessoal e profissional, mas servir de fonte de reflexão e autorreflexão para outros professores/as. O sujeito pode, de forma individual e coletiva, melhorar o exercício profissional, ao compreender as práticas educativas vivenciadas nos tempos sociais e as situações em que as mesmas aconteceram (MONTEIRO, 2002, p. 21).
\end{abstract}

A história de vida presente nos processos de autoformação participada, considera a pessoa enquanto sujeito, objeto de sua própria formação. Este é um processo no qual se percebe a construção e desconstrução de identidades e subjetividades no decorrer do trabalho como educador, de modo que é possível desencadear ações conscientes, responsáveis e comprometidas (MONTEIRO, 2002, p. 6). Como entende Monteiro, é preciso usar uma pluralidade metodológica que nem sempre ratificará a norma; ao contrário, esta pluralidade implicará na transgressão que apela para métodos não convencionais, os quais proporcionam o diálogo com outras formas de conhecimento. É possível, assim, uma escrita pessoal que constrói estilos e gêneros, sendo a ação, como argumenta Morin(200o), além de uma decisão, uma aposta que inclui riscos e incertezas (MONTEIRO, 2002, p.18).

Esta perspectiva nos possibilita olhar por diferentes ângulos, o que não é tarefa fácil ou confortável. Tal processo exige esforço, é um exercício constante. Isto nos conduz a ter um olhar aguçado, crítico e não menos sensível. A cada projeto, estamos constantemente em processo, em transformação. Em tempos de incerteza, instabilidade, provisoriedade do conhecimento, transformações pelas quais somos envolvidos a cada instante, como nos assegura Perez Gomez (1995), temos que estar atentos em relação ao que o mundo contemporâneo sinaliza. A atuação docente é o retrato daquilo em que acreditamos. Revela o lugar em que concebemos este mundo. Expressa o modo como vemos a escola. Sendo assim, corresponder às reais necessidades apresentadas pelo cotidiano escolar contemporâneo é um grande desafio. 
Tal atividade ultrapassa a aplicação prática de teorias ou a repetição de procedimentos e/ou metodologias. Tampouco os conteúdos e as práticas pedagógicas podem ser encarados como simples modelos. Tal desafio se apresenta ao professor /estudante porque as práticas profissionais são cada vez mais marcadas por uma rápida obsolescência da informação e do conhecimento. Trata-se, sobretudo, de possibilidades de ressignificação ao longo do processo formativo. Como nos ensinou Paulo Freire $(1989,1996,2001)$, não nascemos prontos, vamos nos fazendo professores no embate com a prática, com as leituras, com os nossos saberes e não-saberes, com os nossos diálogos e com os nossos monólogos silenciosos. É no exercício do fazer docente que nos confrontamos e construímos uma identidade docente. Reporto-me aqui a Freire e seu conceito de inacabamento, sobre o fato de não nascermos prontos. Não nascemos professores; nós nos tornamos professores no diálogo com o outro e com o mundo. Como Freire argumenta, quando nos reportamos a nossa trajetória profissional, geralmente as referências se concentram nos cursos realizados, na formação acadêmica e experiências que dizem respeito à profissão. Nossa presença no mundo não é levada em conta. É como se, salienta Freire (2001), nossa atividade profissional não fosse, de modo algum, influenciada ou determinada por nossas experiências de menino ou de jovem. Onde estariam nossos desejos, nossos sonhos, nosso bem-querer no mundo ou o próprio desamor à vida (FREIRE, 2001, pp. 79 - 8o).

Somos a pessoa e somos também o profissional. Trazemos os traços de nossa educação, seja ela vivida na escola, nos lares, nas cidades, nas ruas. Seria irresponsabilidade ignorar o papel que a diversidade cultural e social desempenha como espaço formador e educador. As cidades e os campos são também espaços educadores. Como argumenta Brandão, "a educação do homem existe por toda a parte e, muito mais do que a escola, é o resultado da ação de todo o meio sócio-cultural sobre os seus participantes" (BRANDÃO, 1991, p. 47).

Conceber a educação neste sentido é acreditar que nos tornamos alunos, profissionais, pessoas "gestadas" pelas instâncias que vivenciamos. Nesse processo, construímos nossa(s) identidade(s), que não é somente a profissional, mas também a pessoal. Somos a confluência destas esferas que são inseparáveis e que também não constituem uma identidade fixa, única, imutável, são cambiantes, mudam-se, alteram-se. 
A educação que promovemos é fruto destas dimensões. Se queremos que todos tenham acesso à compreensão do mundo, como propõe Guiomar Nammo de Mello, e se queremos que o aluno encare o "desafio de decifrar seu próprio destino, de sua comunidade e o de seu país" é necessário que tal educação inclua os seus sujeitos. Como argumenta Nammo de Mello, "uma pessoa pode nunca sair do seu bairro ou de sua cidade, mas sua visão do mundo será diferente se ela souber que existem outras cidades e países, outros povos e usos" (MELLO, 1990, p. 35). Acreditar nessa dimensão de educação, no poder que ela exerce sobre todos nós, é construir um referencial e uma prática educativa que conceba o outro em todas as suas singularidades. Isto significa ver a pessoa na sua inteireza. Como indaga Laborit, "será que a educação do educador não se deve fazer mais pelo conhecimento de si próprio do que pelo conhecimento da disciplina que ensina?" (LABORIT, 1992, p. 55, Apud NÓVOA, 1995, p. 17). Também como assinala Goodson (1995), há um entrelaçamento entre a história de vida e a história da sociedade, pois todo indivíduo se situa numa relação com a história de seu tempo. Nossas escolhas e opções se dão a partir desta intersecção (GOODSON, 1995, p. 75). O autor ainda nos adverte que histórias de vida de professores tem o poder de modificar os conceitos relativos à escolaridade e currículo (GOODSON, 1995, p. 75).

Estruturar nossa prática docente nessa dimensão éacreditar na história de vida e ressaltar o seu contexto. Trata-se de buscar nossos lugares e até mesmo nossas cicatrizes. Somos os livros que lemos; as imagens que visualizamos e os modos como elas repercutiram em nós; somos os cursos que fizemos; somos a influência familiar que nos moldou; somos os amores que amamos. Nossa formação como educadores está vinculada a estes lugares. E quando olhamos para estes lugares, reconhecendo nossas próprias marcas, compreendemos o processo do outro. Como esclarece Nóvoa (1995), pessoal e profissional são relações simbióticas. Argumenta ele:

Eis-nos de novo face à pessoa e ao profissional, ao ser e ao ensinar. Aqui estamos. Nós e a profissão. E as opções que cada um de nós tem de fazer como professor, as quais cruzam a nossa maneira de ser com a nossa maneira de ensinar e desvendam a nossa maneira de ensinar a nossa maneira de ser. É impossível separar o eu profissional do eu pessoal (NÓVOA, 1995, p. 17). 
Nossa formação se constrói pelos caminhos teóricos e práticos que percorremos. Neste sentido, é fundamental refazer este caminho, olhar para trás e tentar perceber nossos vínculos. Temos que identificar os elos entre as ações, muitas vezes distantes umas das outras. Escolhas profissionais e posicionamentos na vida muitas vezes dialogam entre si, e guardam no fundo a mesma essência. Esta é a procura e o encontro de situações que ligam Educação, Arte e Vida. É necessário, portanto, não perder a linha da nossa história. É preciso revisitar suas marcas. É necessário reconhecer seus traços - retratos de pessoas, situações, vivências calorosas da sala de aula, reminiscências da vida escolar.

Rememorar trajetórias é também reconhecê-las nas nossas escritas - processo esse que não se faz diferente neste momento, onde a escrita se faz na crença de que este caminho pode incluir nossos próprios processos, e fazer com que esta trajetória contribua para a inclusão também do outro. Ao refletir sobre o processo de autoformação, recorro novamente a Monteiro (2002) quando enfatiza a importância do outro nesse contexto:

Essa autoconsciência desenvolvida, permanentemente, de que somos sujeito-objeto em diferentes situações resulta da reflexão e autorreflexão, feito primeiro da realidade externa natural e social que nos cerca e pode permitir elaborarmos a consciência de nós próprios e do outro. Nas relações sociais na variedade de cartografias, família, escola, trabalho, lazer, partido político, igreja, sindicato e outros têm possibilidades de ter consciência da nossa individualidade e sociabilidade (MONTEIRO, 2002, p. 63).

Trata-se aqui de um reconhecimento de nós mesmos através do outro. Como argumenta Bakhtin (1997, p. 378) "tomo consciência de mim, originalmente através dos outros: deles recebo a palavra, a forma e o tom que servirão para a formação original da representação que terei de mim mesmo" (BAKHTIN Apud MONTEIRO, 2002, p. 63). Este é um processo em que, no encontro com o outro, reconhecemos nossas particularidades pessoais e profissionais (MONTEIRO, 2002, p. 63). Aqui rememoro a forma pela qual fui me tornando o que sou. Aproximo-me do passado para me incorporar ao presente, na aproximação cada vez maior entre educação e vida, instâncias que nunca desvinculei uma da outra. Como nas palavras de Paulo Freire, "não nasci, porém, marcado para ser um professor assim. Vim me tornando desta forma no corpo 
das tramas" (FREIRE, 2001, pp. 87-88). Nestas tramas fui tecendo minhas práticas e minha maneira de ser.

\section{Metodologias: seus afastamentos e aproximações}

Incorporar a história do sujeito no seu processo de formação e leitura, outorga a ele mesmo a compreensão de seu posicionamento no mundo. Possibilita o exercício da autoformação, por meio da qual, cada um se situa em seu tempo e em seu lugar. O posicionamento com o qual concordamos muito se distancia dos processos formativos em que predomina a racionalidade técnica. Distancia-se também de processos que concebem a formação e praticam a compreensão da imagem por meio de metodologias e análises unicamente formalistas, que não incluem a história do sujeito-leitor, tampouco o contexto ou história da própria imagem. Precisamos trabalhar numa dimensão que restitua ou reinvente um modelo educacional em que a racionalidade técnica não seja o eixo dos processos educativos. Ao contrário das abordagens mecanicistas e instrumentalistas, acreditamos numa dimensão de construção para a transposição didática na qual “ensinar, é, antes de mais nada, fabricar artesanalmente os saberes tornando-os ensináveis, exercitáveis e passíveis de avaliação" (PERRENOUD, 1993, p. 25).

Ensinar, na perspectiva aqui apresentada, implica em possibilitar que o aluno conheça a magia da necessidade criadora. Mais do que reproduzir obras de arte e imagens tão distantes no tempo (como ainda vemos tão de perto nas práticas escolares), é possibilitar a compreensão desse encantamento e necessidade de se ler e compreender o mundo num processo onde subjetividades individuais e coletivas possam ser afloradas. A forte presença, cada vez maior da imagem na contemporaneidade alerta-nos para a necessidade de repensar o papel destas muitas e tantas outras visualidades que compõe a cena contemporânea.

Precisamos então compreender a história em sua conexão direta com o sujeito - o estudante e também com o professor em formação. É preciso promover o diálogo dos sujeitos da aprendizagem e formação, de modo a relacionar o que é distante com o que é próximo; o que é exterior com o que é realidade interior dos indivíduos. Falo aqui de uma leitura que vá além da abordagem formalista; uma leitura que agregue lugar e contexto. Ainda que muitos estudos, teorias e orientações, encaminhem os processos de leitura numa dimensão que não 
seja somente formalista, as vivências, no plano das licenciaturas, pouco tem incluído da presença de seus sujeitos e pouco tem feito para que a história da arte ou a história da Imagem seja um caminho para a inclusão. Ao contrário, tem-se trabalhado muito no plano dos conteúdos, da linearidade e da cronologia. Para a constatação deste fato, basta olhar para os currículos e ementários das disciplinas oferecidas na sua maioria ao longo dos anos nos cursos de formação. Paulo Freire (1995) reportando-se ao universo da palavra nos orienta que a leitura do mundo precede a mesma e aqui acreditamos que essa leitura de mundo, leitura e compreensão das visualidades deveria também estabelecer relações com o mundo daquele que se forma. Segundo Freire.

A leitura do mundo precede a leitura da palavra, daí que a posterior leitura desta não possa prescindir da continuidade da leitura daquele. Linguagem e realidade se prendem dinamicamente. A compreensão do texto a ser alcançada por sua leitura crítica implica a percepção das relações entre o texto e o contexto (FREIRE, 1995, pp. 11-12).

Esse sentido de leitura e compreensão muito contribui para as nossas reflexões, pois aponta para a participação e história daquele que lê no momento em que lê. Refere-se a um sujeito dono de uma história, de lugares nos quais viveu e vive; que se formou e está se formando. Esta ideia se aproxima daquilo que Efland (2005), nos diz a respeito do quanto o modernismo rejeitou as próprias raízes;

[...] Uma das características centrais do modernismo era a rejeição radical às suas próprias raízes na cultura ocidental. Em seu zelo de reformar e exaltar as artes, artistas e críticos muitas vezes desenfatizavam o folclórico e as tradições populares tanto das culturas ocidentais quanto das não ocidentais, como sendo carentes de significação cultural. Uma conseqüência da elevação da expressão artística a um nível considerado mais alto que a cultura popular foi o isolamento das belas-artes do resto da sociedade transformando-a em um projeto elitista (EFLAND, 2005, p. 174).

Efland (2005) nos mostra quanto o modernismo segmentou e dividiu a cultura e as artes de forma estanque, entre aquelas ditas populares, folclóricas e aquelas chamadas eruditas. Ao segmentarem-se a cultura e as artes, segmentou-se 
também o ser humano, que passou a ser visto de forma isolada e fragmentada; deriva disso indivíduos marginalizados culturalmente. Segundo o autor a pós-modernidade traz o reencontro e a necessidade deste entrelaçamento, onde o conceito de cultura é revisto. As artes e cultura são sintonizadas diretamente com questões sociais, econômicas e as diferentes manifestações culturais em que grupos sociais tem espaço, vez e voz. Assim, eliminamos a fronteira entre baixa e alta cultura.

Esta aproximação entre arte e cultura, e o rompimento de fronteiras, busca eliminar o isolamento e marginalização cultural. A arte, assim como toda a cultura, é fruto de construções e elaborações simbólicas dinâmicas, que dependem de interações constantes entre os indivíduos. Trata-se de uma busca por autenticidade e riquezas escondidas. É papel do professor despertar estas formas culturais escondidas ou desprezadas, mas também é seu papel considerar que há um conhecimento a ser aprendido a partir dos livros e da história da cultura humana.

Acreditamos que educadores e estudantes são sujeitos portadores de uma herança cultural, de saberes e fazeres próprios. As práticas pedagógicas, como a leitura das muitas visualidades que compõem esta imensa paisagem contemporânea guarda estreita relação com lugares e pessoas, assim como com o aprender e ensinar. Que o planejar de nossas aulas possa conter a pessoalidade daquele que planeja e daqueles que irão fazer parte da construção do conhecimento. A aula e a formação são um encontro de pessoas que juntas celebram a aventura da construção do conhecimento. Acreditamos que esta formação é capaz de fazer com que cada um tenha capacidade de ordenar e conquistar sua autonomia, como sujeito criador, desencadeador e mediador do processo de construção de novos conhecimentos, e que esses conhecimentos possam formar pessoas mais livres, criadoras, críticas e autoras dos seus próprios enredos.

Acreditamos que a configuração da aula como criação permite ao professor posicionar-se como sujeito e autor de sua prática; aquele que constrói a aprendizagem a partir de sua história pessoal e de tudo que seleciona e arquiva. Movido pela necessidade de interrelacionar seus saberes profissionais com os outros saberes que estão presentes em sua vida cotidiana, o professor cria o espaço/tempo da aula e da formação, cuja autoria ele divide com seus estudantes. Existe, assim, uma arquitetura e uma identidade 
da formação docente que vai se constituindo nas práticas formativas. Assim como o artista tem um projeto estético, o educador também constrói esteticamente sua prática caracterizada por seus tons, seus coloridos, seus meandros. O estudante não é meramente um copiador e repetidor de conteúdos, mas um sujeito atuante neste processo de aprendizagem (MASETTO, 1992).

\section{Caminhos percorridos, outros a percorrer}

Neste momento apresento como tenho buscado consolidar as proposições e perspectivas descritas até então. Esta é uma tarefa delicada, na medida em que, cada vez mais, o sentido de produção em arte vem sendo alterado, ganhando outros contornos na contemporaneidade. Necessitamos rever nossos próprios procedimentos. Precisamos vislumbrar outras possibilidades voltadas ao aprender e ao ensinar diante de tantas outras visualidades, pois a própria produção contemporânea de arte nos convida e apela para interações entre campos do conhecimento técnico e estético, cada vez mais em trânsito e em constante contaminação. Arte e cultura há tempos se entrelaçaram.

Neste sentido, penso o quanto as contribuições de Ivor Goodson (2007) podem ser importantes neste processo de compreender a formação como o espaço onde se criam as possibilidades para que as narrativas pessoais possam fazer parte da construção curricular e do próprio processo formativo. Segundo Goodson:

Mais do que escrever novas prescrições para as escolas, um novo currículo ou novas diretrizes para as reformas, elas precisam questionar a verdadeira validade das prescrições predeterminadas em um mundo em mudança. Em resumo, precisamos mudar de um currículo prescritivo para um currículo como identidade narrativa; de uma aprendizagem cognitiva prescrita para uma aprendizagem narrativa de gerenciamento da vida (GOODSON, 2007, p. 242).

Pensar em metodologias de ensino é pensar em caminhos, é pensar em construção curricular, é refletir sobre as maneiras possíveis de trilhar um percurso específico para que se chegue a algum lugar, mas que, de modo algum é fixo, estático ou acabado. Penso aqui, o quanto se faz contemporâneo o 
"inacabamento humano" que tanto nos ensinou Paulo Freire. Para isso é imprescindível um olhar direcionado aos processos individuais destes educadores que, inevitavelmente, tem uma trajetória, uma história construída nos seus viveres do mundo e da educação.

Conceber a formação docente numa dimensão como nos aponta Ivor Goodson (2007), uma "aprendizagem narrativa" constitui de algum modo, uma maneira de sairmos do campo de um currículo somente prescritivo e enveredarmos pela possibilidade da construção de um currículo que inclua as vozes daqueles que mais interessam à formação, isto é: aos próprios sujeitos da formação. Desse modo, um currículo que se paute pelo acolhimento das narrativas pessoais, pode ser a possibilidade de entrelaçamento das teorias e práticas efetivas ao processo formativo e construtor de identidades e subjetividades no âmbito da docência e da própria vida.

Assim, parto então do princípio de que não há como pensar a metodologia para o ensino de artes visuais, com estudantes de Artes Visuais, sem que estes estudantes tenham a vivência com as suas próprias visualidades, e que, na construção dos seus processos de compreender a área, (neste caso as Artes Visuais) não falte componentes das suas histórias, das suas narrativas, seus modos singulares de ver e estar no mundo.

Primeiramente, é preciso passar por um lugar que abrigue as histórias particulares, um lugar aconchegante e acolhedor que as entrelace com os fazeres pedagógicos. Tais histórias foram construídas ao longo do tempo e trazem muitos saberes, assim como sabores, às vezes não tão palatáveis, como cada um desejaria.

Nestas experiências que tenho vivido muitos são os objetos trazidos. Cada qual carregado de histórias, de marcas, de sentido, de vida. Muitas construções e trajetórias tem sido narradas, relatadas, descritas, rememoradas passo a passo, sendo que cada um que apresenta seu objeto, descortina ao outro a história de uma vida, reconfigurada em recortes selecionados por uma memória com a qual aquele objeto cumpre o papel de não deixar apagar, cair no esquecimento. Mauad (1997) nos alerta que:

[...] Deve-se atentar para o fato de que a memória vive em permanente tensão entre a ausência e a presença: presença do presente que se lembra do passado esvanecido, mas também presença do passado que irrompe o presente (MAUAD, 1997, p. 4). 
Ao apresentar o objeto, emoções são afloradas. Algumas histórias transpareciam ser muito queridas. Outras, segundo seus próprios protagonistas, nem tão queridas assim. Há aqui algo que muito interessa a todos aqueles que trabalham com arte e com a educação: aprender a lidar também com a dor, a falta, a perda, aprender a lidar com aquilo que nos incomoda. Madalena Freire (1997), autora que escolhi para ajudar-nos nesta construção, nos diz que:

$\mathrm{O}$ educador educa a dor da falta. Educa a fome do desejo. O educador educa a dor da falta cognitiva e afetiva para a construção do prazer. É da falta que nasce o desejo. Educa a aflição da tensão, da angústia de desejar. Educa a fome do desejo. Um dos sintomas de estar vivo é a nossa capacidade de desejar e de nos apaixonar, amar e odiar, destruir e construir. Somos movidos pelo desejo de crescer, de aprender, e nós, educadores, também de ensinar [...] (FREIRE, 1997, p.6-7).

O espaço da aprendizagem é, portanto, construído neste espaço da falta, da dor, daquilo que eu preciso enquanto sujeito. Sujeito este que tem e traz uma história e vai assim acrescendo, transformando em conjunto, em comunhão uns com os outros. Faz-se necessário criar um espaço para falar, ouvir e ser ouvido. O processo aqui descrito exigiu que construíssemos este espaço de confiança. Ecléa Bosi (1995) nos alerta para o cuidado que devemos ter quando vamos lidar com as narrativas na pesquisa. Aqui tomo a formação e esta metodologia enquanto pesquisa. Caldas (2003) ao citar Bosi (1995) sobre estas questões nos informa que:

[...] Para Ecléa Bosi é necessário que o pesquisador sofra de maneira irreversível o destino dos sujeitos observados, criando "um vínculo de amizade e confiança com os recordadores" (1995, p. 37). A partir de uma postura de entrega, expressa prática e teoricamente pelos sujeitos envolvidos (pesquisador e recordadores), formam uma "comunidade de destino", criando as condições para que 'se alcance a compreensão plena de uma dada condição humana' (CALDAS, 2003, p.1).

Essa postura/dimensão da acolhida, da amizade, da confiança é um processo que se constrói, não existe a priori; tal postura vai estabelecendo ou não, dependendo das maneiras como cada um encaminha os processos de pesquisa/formação. Vejo que o processo na disciplina foi sendo consolidado por 
meio do espaço propício que se criou para cada um se abrir para ouvir e ser ouvido. Foi necessário sairmos daquilo que queríamos escutar e ouvir verdadeiramente o outro, sem pré-concepções.

Os objetos foram capazes de aguçar as narrativas pessoais. A partir das falas e histórias, contadas por meio dos objetos, foram se destacando a importância da família, da religiosidade, dos vínculos, do lugar, da infância, do casamento, das perdas. Enfim, das vivências socioafetivas e da cultura de base de cada um. Suas narrativas/objetos falaram da história da cultura, do entrelaçamento de vidas, de gerações que vão se passando, cujos valores vão se perpetuando. Como assevera Bosi (1994) "Mais que um sentimento estético ou de utilidade, os objetos nos dão um assentimento à nossa posição no mundo, à nossa identidade. Mais que da ordem da beleza, falam a nossa alma em sua doce língua natal" (BOSI, 1994, p.441).

Assim, podemos nos perguntar: será que estes temas não aparecem ou reaparecem na arte? Será que a arte é algo tão acima da vida assim? Será que nossos temas, histórias, objetos não fazem parte do universo da arte? Invisto numa perspectiva em que as temáticas das nossas vidas estão presentes nas produções artísticas e culturais, construídas pelas mãos humanas - por mãos individuais e coletivas - desde o tempo da pré-história. Cada tempo criou suas imagens. Cada tempo contou, por meio da pessoa humana suas histórias: histórias de luta, de ganhos, de medos, de fracassos, de conquistas, de famílias, de infâncias, de amores, dores, religiosidades, cultos, vínculos afetivos. Mudam-se os tempos, as maneiras de representação ou apresentação, mas as temáticas são recorrentes.

Os objetos foram capazes de ativar a memória afetiva de cada um e fazer conhecer mais, a mim e ao outro. A percepção e o entendimento de que a memória pode ser vista por múltiplos aspectos, possibilitou identificar pontos comuns que habitam cada um de nós. E, ainda que, cada objeto seja diferente um do outro e carregue as impressões e a história individual, os encontros entre um, dois ou mais participantes, ocorreram nos reencontros com histórias muito próximas. São muitas vezes épocas e tempos aproximados, lugares, espaços, infâncias, famílias, pessoas, avós, avôs. Situações de trabalho, do lazer, lembranças dos sabores, dos vínculos afetivos, dos segredos de famílias. Foi possível também, aprender a partir das perdas, das quais as presenças 
dos objetos nos falavam. Falar das ausências por meio das presenças. No fundo, estes objetos nos falaram e falam de memória e identidade. Sabe-se que ambas, memória e identidade, são cunhadas na cultura de origem em consonância com o diverso, com o outro. Cada um pode acompanhar a história e os deslocamentos do objeto do outro, e estes deslocamentos vão dizendo sobre as cidades, e sobre as experiências tidas nos lugares por onde passaram.

Para Gonçalves (2005, p. 03) "[...] Acompanhar o deslocamento dos objetos ao longo das fronteiras que delimitam esses contextos é em grande parte entender a própria dinâmica da vida social e cultural, seus conflitos, ambigüidades e paradoxos, assim como seus efeitos na subjetividade individual e coletiva. [...]".

Entrelaçar estas narrativas pessoais, memórias, marcas advindas da vida de professores com conteúdos relativos às artes visuais tem suscitado pensar a interferência do tempo no processo de formação docente. O que nos guia no momento da formação é o como constituir esses novos tempos pedagógicos que nos atravessa de várias maneiras por outros tempos? Como incorporar ou fazer conviver simultaneamente diferentes espaços-tempos na escola? Espaços-tempos estes que possibilitem dar voz a este sujeito prenhe de histórias e visualidades?

Penso aqui no espaço/tempo no qual este professor construiu e está construindo a sua identidade docente. Vislumbro, por meio deste caminho metodológico, onde a narrativa ocupa lugar central, a possibilidade de fazer com que cada um possa entrelaçar seus diferentes tempos: o tempo do relógio e o tempo vivido. Em tempo real, existe a narrativa, o compartilhar das memórias. Neste tempo presente fala-se do vivido; como tecelões e tecelãs da própria história, narram memórias que estão depositadas nestes objetos. Em Chronos, o tempo objetivo e cronológico da narrativa, coexiste a dimensão Kairós, onde cada um dá o matiz da sua própria história. Num movimento pendular, presença e ausência, seguindo outro tempo e ritmo, vão se alternando, desvelando assim, por meio de uma leitura e uma narrativa singular, um universo pessoal e íntimo, deixando aparecer visualidades de si e do mundo, num processo lento, respeitoso e dialógico, no qual subjetividades individuais e coletivas vão, pouco a pouco, revelando um universo rico e intenso de visualidades.

Desta maneira, em Tempo real, Chronos e Kairós se encontram e, de uma maneira delicada, cada um dos integrantes 
do grupo vai encontrando sua própria localização na busca de uma formação docente, legitimando, assim, a importância das suas narrativas, das suas visualidades, das histórias de vida enquanto sujeitos fazedores de histórias, arte, educação e da própria vida.

Para que isso pudesse acontecer foi necessário que houvesse um acolhimento. Foi necessário o despir-se das ideias pré-concebidas e um caminhar na direção ao outro. É preciso permitir que o outro inclua a si próprio no processo de aprendizagem, e que assim, a compreensão das visualidades seja, antes de tudo, um posicionamento - mesmo que sutil no espaço da significação. Talvez não seja tão fácil desvelar ou revelar, na medida em que estivemos tão acostumados a nunca dizer nada sobre nós mesmos. Assim, é preciso ampliar as possibilidades de modo a fazer proposições que facilitem este percurso. Isto implica numa concepção de educação dialógica, desprovida de verdades únicas.

\section{Considerações finais}

Os dados (vozes) colhidos, descritos e revelados aqui ultrapassam os limites impostos pela concepção do ensino e formação docente que ignora as referências pessoais do educando, bem como as do professor. Essa reflexão leva ao reconhecimento da riqueza que reside nas histórias pessoais e no encontro destas com o conhecimento legitimado da História da Arte. A apresentação deste processo de formação com incursão pela história pessoal e diálogo com imagens e suas leituras, representa a possibilidade concreta de busca por uma metodologia da presença. Este caminho evidencia também a importância dos projetos de trabalho, sem os quais, corremos grande risco de repetir os modelos de transmissão de conteúdos. O projeto de trabalho dinamiza, torna vivo o conhecimento e sua construção; deriva significações, instiga à pesquisa, e multiplica visões. As reflexões aqui apresentadas relacionam-se diretamente com a recepção crítica da imagem articulada nos processos de formação docente. Embora tratemos da leitura de objetos, tais processos desencadeiam, na perspectiva aqui proposta, um posicionamento que proclama uma atitude crítica perante as manifestações culturais, e que, ao mesmo tempo, conduz a aprendizagem a uma busca cada vez mais profunda do contato e recepção crítica das manifestações visuais na contemporaneidade. As limitações cotidianas do ambiente institucional da formação docente, e até 
mesmo das cidades onde este se situa, podem oferecer obstáculos à vivência e experiência estética da recepção. Porém, a partir desta perspectiva aqui delineada, é possível vislumbrar não somente a leitura de imagens, mas também a construção de uma metodologia que, sobretudo, tenha o cuidado de tornar visível e vivo o encontro e a compreensão das muitas outras visualidades que compõem o mundo contemporâneo. E de que estas visualidades guardem vínculos com aquele que a sente e percebe, lê, interpreta e compreende a si e o mundo.

\section{Referências}

ALBERONI, Francesco. Valores: o bem, o mal, a natureza, a cultura, a vida. Tradução: Y. A. Figueiredo. Rio de Janeiro: Rocco, 2000.

BOSI, Ecléa. Memória e Sociedade: lembranças de velhos. 3 ed. São Paulo: Companhia das Letras, 1995.

BRANDÃO, Carlos Rodrigues. O que é Educação. São Paulo: Brasiliense, 1991.

CALDAS, Fabíola Lins. A memória construída: Comunidade de Destino, Colônia e Rede. Universidade Federal de Rondônia (UFRO) Centro de Hermenêutica do presente, primeira versão, ano II, 꾸므 - novembro - Porto Velho, 2003. volume VIII. Disponível em: http://www.primeiraversao. unir.br/atigos_pdf/numero123fabiola.pdf

EFLAND, Arthur. Cultura, Sociedade, Arte e Educação num Pós - Moderno. In: GUINSBURG, J.; Ana Mae Barbosa (Orgs). O Pós Modernismo. São Paulo: Perspectiva, 2005, pp. $173-188$.

FREIRE, Madalena. Observação-registro-reflexão: instrumentos metodológicos I. São Paulo: Espaço Pedagógico, 1997.

FREIRE, Paulo. Política e Educação. São Paulo: Cortez, 2001. . A Importância do Ato de Ler: em Três Artigos que se Completam. São Paulo: Cortez, 1995, 1997.

GONÇALVES, José Reginaldo Santos. Antropologia dos Objetos: coleções, museus e patrimônios. Rio de Janeiro, Revista brasileira de informação bibliográfica em Ciências Sociais; EDUSC, 2005, Vol: 6o, Fascículo: 6o; p. 7- 26.

GOODSON, Ivor F. Dar voz ao professor: As Histórias de Vida dos Professores e o seu desenvolvimento Profissional. In: NÓVOA, António (Org). Vidas de Professores. Porto: Porto Editora, LDA, 1995. 
. Políticas do conhecimento: vida e trabalho docente entre saberes e instituições. (Org. e tradução: Raimundo Martins e Irene Tourinho). Coleção Desenredos, Goiânia: PPGACV, 2007.

HERNÁNDEZ, Fernando. Cultura Visual, Mudança Educativa e Projeto de Trabalho. Porto Alegre: ARTMED, 2000.

MARTINS, Mirian Celeste Ferreira Dias. Conceitos e Terminologia: Aquecendo uma transforma-ação: Atitudes e Valores no Ensino de Arte. In. BARBOSA, Ana Mae (Org.). Inquietações e Mudanças no Ensino da Arte. São Paulo: Cortez, 2002, pp. 49-6o.

MARTINS, Raimundo. Das belas artes à Cultura Visual: enfoques e deslocamentos. In: MARTINS, Raimundo (Org) Visualidade e Educação. Goiania, FUNAPE, 2008. (Coleção desenredos).

MASSETO, Marcos. Aulas Vivas. São Paulo: MG Editores Associados, 1992.

MAUAD, Ana. M. História, Iconografia e Memória. In: SIMSON, Olga R. de M. Von (org.). Os Desafios Contemporâneos da História Oral. Campinas: UNICAMP/CMU, 1997

MELLO, Guiomar Nammo de. Social Democracia e Educação: Teses para Discussão. São Paulo: Cortez, 1990.

MONTEIRO, Lis Albene. Autoformação, histórias de vida e construções de identidades do/a educador/a. São Paulo: PUC, 2002, p 304. (Tese de Doutorado)

NÓVOA, António. Profissão professor. Porto: Porto, 1995. . Os Professores e as Histórias de sua Vida. In: NÓVOA, António (Org). Vidas de Professores. Porto: Porto, LDA. 1995.

PERRENOUD, Philippe. Práticas pedagógicas formação docente e formação: Perspectivas sociológicas. Lisboa: Dom Quixote, 1993.

PEREZ GÓMEZ, A. P. O pensamento prático do professor: a formação do professor como profissional reflexivo. In: NÓVOA, Antonio (Org.). Os professores e sua formação. Lisboa: Publicações Dom Quixote, 1995, p. 95-114.

PILLAR, Analice Dutra. Leitura e releitura. In: PILLAR, Analice Dutra (org.). A educação do olhar no ensino de artes. Porto Alegre: Mediação, 1999.

SANTOMÉ, Jurjo Torres. As Culturas Negadas e Silenciadas no Currículo. In: SILVA, Tomaz Tadeu da. Alienígenas na Sala de Aula: Uma Introdução aos Estudos Culturais em Educação. Petrópolis: Vozes, 2001. 
STRATICO, José Fernando A. Aesthetic Literacy In: Art Education Discourses outside USA and UK. Proceedings of the XVIII Congress of the International Association of Empirical Aesthetics. Lisbon: Fundação Calouste Gulbenkian, Fundação Luso -Americana, 2004, pp. 356-359.

TARDIF, Maurice. Saberes Docentes e Formação Profissional. Petrópolis: Vozes, 2002.

TOURINHO, Irene. Cultura, Currículo e Avaliação. In: Licenciatura em artes visuais: módulo 5/ Universidade Federal de Goiás. Faculdade de Artes Visuais. Goiânia: Editora da UFG, Funape, 2009.

NOTAS

$1 \mathrm{O}$ termo leitura neste texto está inteiramente baseado na perspectiva freiriana, onde o próprio Freire adverte que a leitura do mundo precede a leitura da palavra. Maiores informações em FREIRE, Paulo. A importância do ato de ler em três artigos que se completam. 23 $3^{\underline{a}}$ Edição. São Paulo:

Autores Associados: Cortez, 1989.

2 Informações precisas em MORIN, Edgar. Os sete saberes necessários à educação do futuro. Trad. de Catarina Eleonora F. da Silva e Jeanne Sawaya. - 2. Edª - São Paulo : Cortez ; Brasília, DF : UNESCO, 2000.

Recebido em: 07/10/2013

Aceito em: 08/11/2013 
RONALDO ALEXANDRE DE OLIVEIRA rolivı@gmail.com

Professor Adjunto do Departamento de Arte visual da Universidade Estadual de Londrina, UEL, Paraná. Tem experiência na área de arte e educação, com ênfase em currículo e formação inicial e continuada de professores de artes visuais. 